MEDICAL GENETICS IN PRACTICE

\title{
Letting the family know: balancing ethics and effectiveness when notifying relatives about genetic testing for a familial disorder
}

\author{
G K Suthers, J Armstrong, J McCormack, D Trott
}

See end of article for authors' affiliations

Correspondence to Dr G Suthers, Familial

Cancer Unit, South

Australian Clinical

Genetics Service,

Department of Genetic

Medicine, Children's Youth

and Women's Health

Service, North Adelaide,

SA 5006, Australia;

graeme.suthers@cywhs.sa.

gov.au

Received 26 October 2005

Revised version received

13 December 2005

Accepted for publication

15 December 2005

Published Online First

21 December 2005
Objective: To increase the awareness among at risk relatives of the availability of genetic testing for a familial disorder while respecting their autonomy and privacy.

Methods: This was a comparison of preintervention and postintervention cohorts of families carried out in a state wide clinical service providing genetic counselling and testing for people at risk of familial adult onset cancer. Unaffected relatives who were not clients of the service in 74 kindreds with familial mutations causing familial breast and ovarian cancer, hereditary non-polyposis colorectal cancer, or Cowden syndrome were included in the study. In the baseline cohort (41 kindreds), family members who were clients of the clinical service and had been shown to be carriers of mutations were asked to advise relatives that genetic testing was available. In the intervention cohort (33 kindreds), the clinical service obtained consent to advise at risk relatives by letter that genetic testing was available. The main outcome measures were: (a) proportion of unaffected first and second degree relatives of the proband in each family whose genetic status was clarified within 2 years of the mutation being identified in the family, and (b) concerns regarding privacy and autonomy voiced by relatives receiving these letters.

Results: In the baseline cohort, the average proportion of relatives in each family whose genetic status was clarified was $23 \%$. In the intervention cohort, the average proportion of relatives in each family whose genetic status was clarified was $40 \%(p=0.001)$. None of the relatives in the intervention cohort complained of a breach of privacy or autonomy.

Conclusion: Clinical services can take an effective and proactive approach to notifying relatives who are not their clients of the availability of genetic testing without compromising principles of privacy and autonomy.
G enetic testing is increasingly being used in the management of familial disorders. Identifying the causative mutation may not alter the medical care offered to the patient, but it does allow the genetic status of unaffected at risk relatives to be clarified. These relatives may seek presymptomatic genetic testing as a prelude to making significant reproductive or medical decisions, or to facilitate such decision making by their children. Those identified as carriers can undertake strategies to reduce their risk of disease or facilitate early diagnosis, and non-carriers can avoid the costs of unnecessary interventions. Both outcomes yield benefits to individuals and society.

The uptake of presymptomatic genetic testing among relatives varies greatly and is influenced by a variety of social, genetic, and psychological factors. ${ }^{1-5}$ For the patient identified with the mutation, the process of advising relatives that genetic testing is available is by no means simple..$^{6-13}$ There has also been extensive debate about the need to respect the privacy of those undergoing genetic testing, the rights of their relatives to be notified of significant genetic information, and the extent to which families or service providers should be responsible for notifying them. ${ }^{14-23}$ Conversely, relatives may regard the unsolicited provision of information about a familial disorder as an invasion of their own privacy, with the potential for adverse psychological and financial (for example, insurance) consequences. There is also the possibility that at risk relatives could feel pressured by family members to pursue presymptomatic genetic testing. The challenge for those providing clinical programmes is to devise a process for advising relatives that addresses these diverse and competing requirements. With the advent of genetic testing for common familial disorders such as familial cancer, familial hypercholesterolaemia, and hereditary cardiomyopathies, there is a need to develop efficient, effective, and acceptable procedures for informing relatives.

The South Australian Familial Cancer Service (FCS) provides genetic services for patients with familial cancer and their families. We initially left the dissemination of genetic information to relatives in the hands of the family members who were already clients of our service, but the low uptake of presymptomatic genetic testing among these relatives suggested that information about the availability of genetic counselling and testing was not being effectively shared within families. We have trialled a process for informing relatives that meets the competing requirements of disseminating information with significant medical and social consequences while respecting principles of privacy and autonomy. This process could be readily applied in other settings.

\section{METHODS}

\section{Clinical setting}

The FCS was established in 1998 as the sole provider of genetic education, counselling, and testing for familial cancer in the State. These services are provided at no direct cost to clients. The FCS does not provide cancer surveillance, diagnostic, or therapeutic services, but liaises closely with other established service providers.

Abbreviation: FCS, Familial Cancer Service 
The kindreds selected for this study had autosomal dominant mutations responsible for adult onset familial cancer syndromes: familial breast/ovarian cancer (BRCAI and $B R C A 2$ genes; 56 kindreds), hereditary non-polyposis colorectal cancer ( $M L H 1, M S H 2$, and MSH6 genes; 17 kindreds), and Cowden syndrome (PTEN gene; one kindred). There was a minimum of 2 years' follow up after each kindred's mutation had been identified, and all follow up was censored at 31 December 2004. The analysis was initially restricted to eligible unaffected first and second degree relatives (hereafter described as close relatives) of the first person in the family identified with the mutation (the proband). These relatives were at $25-50 \%$ risk of being carriers of the mutation. To be eligible for presymptomatic testing through the FCS, a close relative had to reside in South Australia, not have had a diagnosis of cancer, and be aged 16 years or older.

Probands had genetic testing initiated by the clinic on the basis of the reported family history; relatives were not necessarily contacted by the FCS as a prelude to such testing. Approximately $85 \%$ of the kindreds were also involved in research studies. These studies did not involve the provision of genetic information or advice to subjects, and the baseline and intervention cohorts (described below) had the same proportions of research kindreds. Hence the impact of the intervention could be assessed independently of the effect of involvement in research.

\section{Intervention strategy}

Prior to 2001, probands with a heritable mutation were advised that close relatives were at high risk of having the same mutation. It was recommended both at the appointment and in a subsequent telephone call and letter that the proband should advise close relatives to seek further information from their doctor or the FCS. The baseline cohort of families was drawn from this experience.

From 2001, the Service began writing directly to the close relatives of documented carriers in newly identified kindreds to advise them of the cancer risk and availability of genetic counselling and testing. These kindreds constituted the intervention cohort. This process was not designed to replace the sharing of information among relatives by word of mouth, but was established as a supplementary process. The following process was approved by the institutional ethics committee:

1. As part of pretest counselling, the proband was requested to acknowledge the role of the Service in advising relatives. The wording in the consent form was, "I understand that the diagnosis of familial cancer may have implications for other members of my family and that I may be asked to assist the Familial Cancer Service in informing them". Acceptance of this request was encouraged but was not mandatory.

2. Once a mutation had been identified, the proband provided contact details for adult close relatives residing in South Australia or elsewhere in Australia. Contact details were not sourced or validated from other sources (thereby ensuring that the proband controlled the process).

3. The FCS sent a letter to each close relative. The timing of this letter was decided with the proband to allow for informal contact with relatives. Some probands were keen to contact their relatives informally, others agreed with reluctance, while others declined to do so and were relieved that the unit would notify their families.

4. The wording of the letter was in general terms and did not identify the proband (thereby protecting the proband's privacy) or the familial cancer syndrome, mutation, or details of cancer risk (thereby reducing the potential for adverse impact on the recipient's insurability in Australia). The text of the letter and response sheet are shown in the appendix (figs A and B).

5. If the proband was unwilling to provide contact details but agreed to contact the relative, the letter was given to the proband to pass to the relative.

6. South Australian relatives who sought further information were offered an appointment; interstate relatives were directed to their local services. The proband was not advised which relatives responded to the letter (thereby protecting the privacy of relatives).

7. If presymptomatic genetic testing identified another carrier, the carrier was asked to provide contact details for other close relatives (as in step 2 above), and the cycle was repeated. The further medical management of the carrier was arranged through their general practitioner and local specialist services.

8. The FCS did not seek further contact with relatives who did not respond to the letter, even if another carrier subsequently provided the relative's contact details (thereby avoiding the risk of harassing those who did not want information).

This intervention only applied to relatives who were not already clients of the FCS. Relatives who had already attended appointments prior to a mutation being identified were advised by letter of the mutation, the associated cancer risks, and that genetic testing was available.

For data management, we used a hybrid system consisting of the Progeny database (www.progeny2000.com) and the KinTrak client interface (www.kintrak.com). This combination allowed for simultaneous graphical review of a pedigree and efficient manipulation of textual data.

\section{Outcome measures}

The FCS encouraged clients to make informed choices regarding genetic testing and cancer surveillance. Relatives who made an informed choice not to have testing could have represented as successful an outcome as those who proceeded with testing, but it was impossible to quantify the degree to which this goal was achieved. For this reason, the number of close relatives whose genetic status was defined was used as a surrogate measure of outcome. Genetic status was determined either by genetic testing or by a parent being shown to be a non-carrier (thereby precluding their children from inheriting the mutation from this parent, and making the children presumed non-carriers); none of the presumed non-carriers subsequently sought genetic testing to confirm the inferred genetic status.

The $\chi^{2}$ test or two tailed $t$ test was used to assess the significance of differences between the two cohorts.

\section{RESULTS}

\section{Effect of letters versus no letters within first 2 years}

The characteristics of the two cohorts and the outcome of genetic testing within the first 2 years of a mutation being identified in the proband are summarised in table 1 . The response in different families varied markedly. In both cohorts, there were families in which no presymptomatic genetic testing of close relatives was performed within the first 2 years, and others in which all eligible close relatives had their genetic status defined promptly. On average, $23 \%$ of close relatives in families in the baseline cohort had their genetic status defined within 2 years compared with $40 \%$ in families from the intervention cohort $(p=0.001)$.

Of the 442 close relatives in the intervention cohort, contact details were provided for 140 who were then sent a letter by the FCS. A further 39 letters were provided via 
Table 1 Outcome in baseline (B) and intervention (I) cohorts in first 2 years

\begin{tabular}{lccl}
\hline Parameter & B & I & p value \\
\hline No. of probands & 41 & 33 & \\
Total no. of probands' close relatives & 411 & 442 & \\
(all states) & & & \\
Average age of probands (years) & 52.3 & 52.0 & 0.9 \\
No. of female probands & 37 & 31 & 0.6 \\
No. of breast cancer kindreds & 31 & 25 & 1.0 \\
No. of close relatives per proband & 10.0 & 13.4 & 0.07 \\
No. of close relatives tested in SA & 62 & 88 & \\
No. of close relatives shown to be & 27 & 59 & \\
presumed non-carriers in SA & & & \\
Total no. of close relatives with carrier & 89 & 147 & \\
status defined in SA & & & \\
Average proportion of close relatives in & $23 \%$ & $40 \%$ & 0.001 \\
each kindred with genetic status defined & & & \\
in SA & & & \\
\hline SA, South Australia. & & & \\
\hline
\end{tabular}

probands. In families in which one or more letters were provided via the proband, an average of $24 \%$ of eligible close relatives in the family had their genetic status clarified within 2 years of the mutation being identified. In contrast, in families in which all the letters were sent by the Service, an average of $46 \%$ of eligible close relatives in the family had their genetic status clarified within 2 years $(p=0.03)$. Of the 88 relatives in this cohort who sought testing within 2 years, 40 had been posted a letter by the FCS and only two had been provided with a letter via the proband $(p=0.01)$; the remaining 46 relatives who sought testing had not been sent letters because they were already clients of the FCS by the time letters were due to be sent out. The lack of response to letters provided via the proband could reflect the relatives' lack of interest or a failure by the proband to deliver the letter; this issue was not explored.

Approximately $12 \%$ of the relatives in the intervention cohort whose contact details were provided lived outside South Australia and hence their response to the offer of genetic counselling was not necessarily known. If the relatives living outside South Australia had responded to the same degree as those within the state, the overall response rates would have been $14 \%$ higher than shown.

\section{Overall effect of all letters sent to relatives}

Letters were subsequently provided for the probands' close relatives in the baseline cohort. This occurred after 2001 and was more than 2 years after mutations had been identified in these kindreds. Letters were also provided for the close relatives of other carriers in both cohorts-that is, for more distant relatives of probands who were at $25-50 \%$ risk of having the mutation. In the period 2001-2003, the FCS sent 140 letters to close relatives in the intervention cohort (as described above) and an additional 211 letters to other relatives living in South Australia. The FCS also provided 39 letters for probands to pass on to close relatives in the intervention cohort (as described above); an additional 201 letters were provided to pass on to other relatives.

Of the 591 relatives receiving letters by post or via the proband, 19\% sought presymptomatic genetic testing, a further $8 \%$ were identified as presumed non-carriers, and $7 \%$ sought further information from the FCS but did not proceed to have genetic testing. Hence, a total of $34 \%$ of recipients (responders) either had their genetic status defined or sought further information about the availability of genetic testing. The remaining 66\% (non-responders) had not responded by the end of the follow up period (December 2004).
Among all the relatives seeking presymptomatic testing, there was no significant difference in relation to age, gender, or gene involved (BRCAl/2 compared with other genes), between those who had been sent a risk notification letter by the FCS and those who had not (data not shown). In each of the first 3 years after the introduction of the letters, similar proportions of recipients responded within 12 months of a letter being sent $(31 \%, 25 \%$, and $25 \%$ during 2001, 2002, and 2003 respectively; $\mathrm{p}=0.4, \chi^{2}$ test $)$.

When the South Australian relatives who had been sent a letter by the FCS were partitioned into responders and nonresponders, there was no association between response and several parameters (table 2). Relatives who were shown to be presumed non-carriers $(n=13)$ were excluded from this analysis; those who advised us that they did not want information $(n=25)$ were counted as non-responders. The duration of follow up ranged from 12 to 60 months.

\section{Adverse responses to letters}

Of the 351 relatives sent a letter by the FCS, 25 (7\%) contacted us to indicate that they did not want further information about familial cancer risk. None complained of a breach of privacy or sought to have identifying information removed from the unit's database, and no complaints were received by our host institution.

\section{DISCUSSION}

Significance and effectiveness of notifying relatives

The most important clinical benefit arising from the identification of a mutation may be the ability to define the status of at risk relatives who have yet to attend the clinic. Once we began to notify relatives who were not clients of our FCS that genetic testing was available, the proportion of close relatives in each family whose genetic status was clarified within 2 years almost doubled.

There are a number of aspects of this investigation that merit further attention. We did not explore the dynamic between person to person communication about risk and the more formal (and less specific) letter from the FCS, ${ }^{11}$ nor did we try to determine why non-responders elected not to seek further information regarding such a significant health issue. We found that, irrespective of the delay between the kindred's mutation being identified and letters being sent to relatives, the proportion of recipients seeking further information was no higher than $34 \%$. We do not know what factors set this limit, but recognise that issues of confidentiality, fear of cancer, or a perception that surveillance is ineffective may have been involved.

Table 2 Characteristics of responders compared with non-responders

\begin{tabular}{|c|c|c|c|}
\hline & $\begin{array}{l}\text { Sought testing } \\
\text { or information }\end{array}$ & $\begin{array}{l}\text { Did not } \\
\text { seek testing } \\
\text { or information }\end{array}$ & $\mathbf{p}$ \\
\hline No. of relatives & 134 & 204 & \\
\hline $\begin{array}{l}\text { Average age of recipients } \\
\text { (if known) (years) }\end{array}$ & 46 & 47 & 0.5 \\
\hline $\begin{array}{l}\text { No. }(\%) \text { in research } \\
\text { kindreds }\end{array}$ & $120(90 \%)$ & $182(89 \%)$ & 0.9 \\
\hline $\begin{array}{l}\text { No. }(\%) \text { who were close } \\
\text { relatives of proband }\end{array}$ & $67(50 \%)$ & 110 (54\%) & 0.5 \\
\hline $\begin{array}{l}\text { No. }(\%) \text { sent letter more } \\
\text { than } 2 \text { years after } \\
\text { mutation was identified }\end{array}$ & $53(40 \%)$ & $88(43 \%)$ & 0.5 \\
\hline No. (\%) in BRCA kindreds & $104(78 \%)$ & $164(80 \%)$ & 0.5 \\
\hline No. $(\%)$ of male recipients & $67(50 \%)$ & $120(59 \%)$ & 0.1 \\
\hline
\end{tabular}


It is clear that providing letters to relatives via the proband is not as effective as sending letters directly to the relatives. This could reflect the reticence of probands to pass these letters on, or that the proband's inability (or unwillingness) to provide contact details for these relatives reflects a degree of emotional distance from the relative. ${ }^{8}$ A proactive approach by the counsellor can increase the proportion of close relatives to whom the letter is sent by the FCS; in the period 2001-2004, the proportion of relatives sent letters by the FCS (rather than via the proband) increased steadily by $16 \%$ (data not shown).

This study was intrinsically weakened by the use of a historical cohort to provide baseline measures of outcome. The past decade has been a period of increasing public awareness of genetics in healthcare, and this may have resulted in a change in the types of patients seeking genetic counselling and testing, but there were no significant differences in age, sex, or the gene involved in the probands from the two cohorts or among those seeking presymptomatic testing. In each of the first 3 years in which we sent letters to relatives, the response rates were stable and did not suggest that there was a growing interest in genetic testing. These observations do not suggest that there was a systematic change in patient type or attitudes over this period.

\section{Ethical issues in notifying relatives}

There are a host of ethical issues that can complicate the process of a clinical service contacting relatives who are not clients of that service. ${ }^{1018202123}$ The provision of a formal communication to relatives by a service provider has the advantage of reducing the burden on the proband to advise relatives about a medically and ethically complex issue while providing the relatives with greater autonomy in deciding what to do with this information. If this information is provided exclusively by the proband, relatives may feel pressured by the proband's expectations to undertake testing. After all, the proband has already demonstrated an interest in genetic testing that may not be shared by their relatives. The provision of this information by a disinterested service provider gives the family members the opportunity to make some separation between their emotional and genetic relationships.

The strategy outlined in this study provides information to relatives in a staged fashion. In the first step, the formal communication simply advises relatives in very general terms that medically significant information is available. The lack of specific detail provides the family members with another opportunity to separate their emotional and genetic relationships, as it is not assumed that relatives will want to know the implications of diagnoses in other family members. Relatives can readily obtain more detailed information without involving the proband, thereby avoiding the proband's expectation that they will have a presymptomatic genetic test.

The letter sent to relatives requested that those seeking an appointment with the FCS obtain a referral from their general practitioner. While the FCS has a policy of accepting self referrals for genetic counselling and testing, we prefer to have general practitioner involvement from the outset. Of the recipients who sought an appointment, $47 \%$ did not provide a referral. This reflected the convenience of making a prompt appointment with the FCS rather than concerns about confidentiality. During the appointment, those without referrals were asked for permission to provide their doctors with the outcome of presymptomatic testing, and with rare exceptions, this was provided. We have no evidence that concern regarding doctors' access to confidential information was a significant factor in recipients deciding whether to pursue the offer of genetic counselling and testing.

This formal communication could be delivered by the proband or posted directly to the relatives, and there are some ethical distinctions between the two approaches (table 3). Although local attitudes and legislation may determine which method is more ethically appropriate in a specific situation, posting letters directly to at risk relatives seemed to be more effective. The fact that a recipient of such a letter must initiate a request for further information and that the service provider does not follow up non-responders gives the

Table 3 Comparison of ethical issues in sending letters to relatives via proband or by post

\begin{tabular}{|c|c|c|}
\hline \multirow[b]{2}{*}{ Issue } & \multicolumn{2}{|l|}{ Ethical consideration } \\
\hline & Lefter provided via proband & Letter posted by FCS \\
\hline $\begin{array}{l}\text { The proband's decision to have genetic testing } \\
\text { should not be conditional on consent to notify } \\
\text { relatives. }\end{array}$ & \multicolumn{2}{|c|}{ The proband could choose whether to notify relatives. } \\
\hline $\begin{array}{l}\text { The proband's decision to have genetic testing } \\
\text { should not be conditional on involvement in } \\
\text { notifying relatives. }\end{array}$ & $\begin{array}{l}\text { The proband could choose whether to deliver } \\
\text { letters to relatives. }\end{array}$ & $\begin{array}{l}\text { Involvement of the Unit reduced the demand placed } \\
\text { on the proband to notify relatives. }\end{array}$ \\
\hline $\begin{array}{l}\text { The right of the carrier of a mutation to maintain } \\
\text { privacy should be upheld. }\end{array}$ & $\begin{array}{l}\text { The proband could choose to post letters } \\
\text { anonymously. }\end{array}$ & The letter sent by the Unit did not identify the proband. \\
\hline $\begin{array}{l}\text { At-risk relatives should be advised of genetic } \\
\text { risks that may have significant personal } \\
\text { consequences for them. }\end{array}$ & $\begin{array}{l}\text { Lower response rate suggests that some } \\
\text { probands may have failed to pass letter on, } \\
\text { thereby denying relatives the opportunity to } \\
\text { respond. }\end{array}$ & $\begin{array}{l}\text { Higher response rate suggests that more relatives } \\
\text { were given the opportunity to respond. }\end{array}$ \\
\hline The privacy of at-risk relatives should be upheld. & $\begin{array}{l}\text { Contact details of relatives were not provided } \\
\text { by the proband. The Unit did not advise the } \\
\text { proband if relatives sought genetic testing. }\end{array}$ & $\begin{array}{l}\text { Contact details of relatives were only obtained from } \\
\text { the proband. The Unit did not advise the proband of } \\
\text { the responses of relatives. }\end{array}$ \\
\hline $\begin{array}{l}\text { At-risk relatives should be able to decide how } \\
\text { much genetic information they wish to access. }\end{array}$ & \multicolumn{2}{|c|}{ At-risk relatives chose whether to access further information and whether to involve their doctor. } \\
\hline $\begin{array}{l}\text { The notification of genetic risk should not } \\
\text { compromise financial decisions that at-risk } \\
\text { relatives may make. }\end{array}$ & \multicolumn{2}{|c|}{ The general information provided in the letter did not specify the disorder in the family or the degree of risk. } \\
\hline $\begin{array}{l}\text { The interest of multiple relatives in genetic testing } \\
\text { should not take precedence over an individual's } \\
\text { autonomy. }\end{array}$ & $\begin{array}{l}\text { A relative could be provided with multiple } \\
\text { letters by other family members who had } \\
\text { sought genetic testing. }\end{array}$ & $\begin{array}{l}\text { Relatives who did not seek further information were } \\
\text { not approached by the FCS again, even if other } \\
\text { relatives provided their contact details. }\end{array}$ \\
\hline
\end{tabular}


relative control over the process of obtaining and using this information.

The provision of de-identified information by a clinical service does not necessarily provide anonymity for all family members. Informal communication between family members will frequently have identified the proband prior to receipt of the letter from the service. However, the provision of deidentified information without the proband necessarily being involved, as well as the confidentiality of the recipient's response to the clinical service, ensures that anonymity is not compromised by the notification process.

Only two probands refused permission for the FCS to notify relatives. One proband had been in the baseline cohort in which consent for sending letters had not been sought prior to testing; when she was subsequently approached for consent to contact to her relatives, she declined. More recently, a proband who was not part of this study refused permission. There are a couple of factors which may account for the low incidence of this response in South Australia in contrast to other centres. ${ }^{17}$ The FCS does not offer cancer diagnostic or therapeutic services, thereby making it clear that "the family" is the unit of care rather than one person. We also introduce the concept of the "family covenant" ${ }^{24}$ early in the process of our consultation with the proband, highlighting that testing for a heritable mutation defines an attribute of the family rather than just an individual, and that the main beneficiaries of the test are likely to be unaffected family members who have yet to attend the clinic.

None of the recipients of letters from the FCS complained of a breach of their privacy. This may be due to the careful wording of our letter, or it may simply reflect local views about privacy and the role of healthcare providers in South Australia. In our letter, we did not seek to elicit negative responses from recipients and, despite $7 \%$ of recipients advising us that they did not want further information, none complained of such a breach. During the period of this study, three of the 2090 clients referred by doctors to our FCS requested that identifying information be removed from our database, indicating that South Australians are not unaware of their right to privacy. We have also sought publicity for our programme, we have the support of local cancer specialists, and we have highlighted the involvement of a respected philanthropic organisation in funding the programme. We did not examine the degree to which these various factors may have contributed to the lack of adverse responses, and recognise that our strategy might elicit such responses in other settings.

\section{Managing the process of notifying relatives}

Managing the notification, counselling, testing, and subsequent follow up of relatives in an extended family requires a family based data management system. Such a system does not replace the need for expert genetic counselling, but it is necessary for reasons of efficiency (reducing the numbers of staff required) and effectiveness (recognising the medicolegal implications of advising relatives). In 2004, we provided genetic counselling for 800 clients and sent 700 risk advice letters to relatives with the equivalent of only 4.4 clinical staff. Careful record keeping is also essential because of the potential delay between a relative being advised of the availability of genetic testing and the relative seeking such a test. Although the majority of those seeking genetic counselling and testing did so within 18 months of receiving a letter, there were continuing requests for information 4 years later.

\section{CONCLUSION}

A programme of genetic testing for a familial disorder must reach beyond the affected patient and address the potential needs of at risk relatives. Clinical services can provide useful information to relatives who are not their clients without compromising principles of privacy and autonomy. The complexities of managing genetic testing in families demand careful planning, expert genetic counselling, and sophisticated data management. However, the service's proactive approach to notifying relatives results in a much greater proportion of at-risk relatives making informed decisions about genetic testing for the family's disorder.

\section{ACKNOWLEDGEMENTS}

We thank all past and present members of the Familial Cancer Unit and its antecedents for their assistance in developing and implementing this procedure. $\mathrm{K}$ van Diemen and $\mathrm{K}$ O'Doherty assisted with data management, and K O'Doherty also critically reviewed the manuscript. J Suthers provided invaluable statistical advice. Funding of the Familial Cancer Unit is provided by the South Australian Department of Health and The Cancer Council, SA.

\section{Authors' affiliations}

G K Suthers, J Armstrong, J McCormack, D Trott, Familial Cancer Unit, South Australian Clinical Genetics Service, Department of Genetic Medicine, Children's Youth and Women's Health Service, North Adelaide, Australia

G K Suthers, Department of Paediatrics, University of Adelaide, Australia

Funding of the Familial Cancer Service is provided by the South Australian Department of Health and The Cancer Council SA; these organisations were not otherwise involved in any aspect of this study.

Competing interests: The Women's and Children's Hospital receives a share of royalties from sales of the KinTrak database. As an employee of the Hospital, G K Suthers has been seconded to provide consultancy services for KinTrak International. D Trott has provided consultancy services to KinTrak International. J McCormack and J Armstrong have no competing interests.

\section{REFERENCES}

1 van der Steenstraten IM, Tibben A, Roos RAC, van de Kamp JJP, Niermeijer MF. Predictive testing for Huntington disease: nonparticipants compared with participants in the Dutch program. Am J Hum Genet 1994;55:618-25.

2 Mehlman MJ, Kodish ED, Whitehouse P, Zinn AB, Sollitto S, Berger J, Chiao EJ, Dosick MS, Cassidy SB. The need for anonymous genetic counselling and testing. Am J Hum Genet 1996;58:393-7.

3 Aktan-Collan K, Mecklin JP, Jarvinen H, Nystrom-Lahti M, Peltomaki P, Soderling I, Uutela A, de la Chapelle A, Kaariainen H. Predictive genetic testing for hereditary non-polyposis colorectal cancer: uptake and long-term satisfaction. Int J Cancer 2000;89:44-50.

4 Bodd TL, Reichelt J, Heimdal K, Møller P. Uptake of BRCA1 genetic testing in adult sisters and daughters of known mutation carriers in Norway. J Genet Couns 2003;12:405-17.

5 Brooks L, Lennard F, Shenton A, Lalloo F, Ambus I, Ardern-Jones A, Belk R, Kerr B, Craufurd D, Eeles R, Gareth Evans D. BRCA1/2 predictive testing: a study of uptake in two centres. Eur J Hum Genet 2004; 12:654-62.

6 Julian-Reynier C, Eisinger F, Chabal F, Lasset C, Nogues C, Stoppa-Lyonnet D, Vennin P, Sobol H. Disclosure to the family of breast/ovarian cancer genetic test results: patient's willingness and associated factors. Am J Med Genet 2000;94:13-18.

7 Tercyak KP, Hughes C, Main D, Snyder C, Lynch JF, Lynch HT, Leman C. Parental communication of BRCA1/2 genetic test results to children. Patient Educ Couns 2001;42:213-24.

8 Hughes C, Lerman C, Schwartz M, Peshkin BN, Wenzel L, Narod S, Corio C, Tercyak KP, Hanna D, Isaacs C, Main D. All in the family: Evaluation of the process and content of sisters' communication about BRCA1 and BRCA2 genetic test results. Am J Med Genet 2002; 107: 143-50.

9 Wagner Costalas J, Itzen M, Malick J, Babb JS, Bove B, Godwin AK, Daly MB. Communication of BRCA1 and BRCA2 results to at-risk relatives: a cancer risk assessment program's experience. Am J Med Genet 2003;119C:11-18.

10 Claes E, Evers-Kiebooms G, Boogaerts A, Decruyenaere M, Denayer L, Legius E. Communication with close and distant relatives in the context of genetic testing for hereditary breast and ovarian cancer in cancer patients. Am J Med Genet 2003;116A:11-19.

11 Forrest K, Simpson SA, Wilson BJ, van Teijlingen ER, McKee L, Haites N, Matthews E. To tell or not to tell: barriers and facilitators in family communication about genetic risk. Clin Genet 2003;64:317-26. 
12 Segal J, Esplen MJ, Toner B, Baedorf S, Narod S, Butler K. An investigation of the disclosure process and support needs of BRCA1 and BRCA2 carriers. Am J Med Genet 2004; 124A:267-72.

13 McGivern B, Everett J, Yager GG, Baumiller RC, Hafertepen A, Saal HM Family communication about positive BRCA1 and BRCA2 genetic test results. Genet Med 2004;6:503-9.

14 Skene L. Patients' rights or family responsibilities?: two approaches to genetic testing. Med Law Rev 1998;6:1-41.

15 Lehmann LS, Weeks JC, Klar N, Biener L, Garber JE. Disclosure of familial genetic information: perceptions of the duty to inform. Am J Med 2000;109:705-11.

16 Kerzin-Storrar L, Wright C, Williamson PR, Fryer A, Niindou A, Quarrell O, Donnai $D$, Craufurd D. Comparison of genetic services with and without genetic registers: access and attitudes to genetic counselling among relatives of genetic clinic patients. J Med Genet 2002;39:e85.

17 Falk MJ, Dugan RB, O'Riordan MA, Matthews AL, Robin NH. Medical geneticists' duty to warn at-risk relatives for genetic disease. Am J Med Genet 2003;120A:374-80.

\section{APPENDIX}

\section{Dear}

The Familial Cancer Unit is part of the South Australian Familial Cancer Service. I am writing to you at the request of one of your relatives because they wish to share important health information with you.

A member of your family has been found to have an inherited tendency to develop cancer. This may mean that there is an increased chance of you developing cancer. Even if people have not developed cancer themselves, they can pass this inherited tendency to their children. If a person has an increased chance of developing cancer, there are effective ways of reducing this risk.

\section{What can you do now?}

We recommend that you discuss this letter with your doctor. We can provide your doctor with further information about the family's situation as well as assistance in managing your cancer risk.

We also recommend that you discuss this matter with a counsellor at a genetics clinic.

A genetic counsellor can offer you:

Assessment about your chance of having this condition or of developing cancer.

Advice to you and your doctor about managing your chance of developing cancer.

Genetic testing is now available if you want to know whether you have inherited the family's tendency to develop cancer or not. There is no obligation for you to have a test.

Research studies about inherited cancer are available for some families.

Please let us know if you would like to find out more about the services available to you by indicating your response on the enclosed form and sending it back to us. These services are available at no cost to you. Please be assured that the information we give you and any information we receive from you is treated confidentially.

\section{We urge you to take this matter seriously as this} information can be life saving.

Please do not hesitate to call the Unit if you have any concerns or questions.

Yours sincerely,

Head, Familial Cancer Clinic

Figure A Text of letter provided by the Familial Cancer Unit to close relatives of the proband or other carriers. The letter was either sent by mail directly to the relative or sent via the proband.
18 Hodge JG. Ethical issues concerning genetic testing and screening in public health. Am J Med Genet 2004; 125:66-70.

19 Andorno R. The right not to know: an autonomy based approach. J Med Ethics 2004;30:435-9.

20 Offit K, Groeger E, Turner S, Wadsworth BA, Weiser MA. The 'duty to warn' a patient's family members about hereditary disease risks. JAMA 2004;292: 1469-73.

21 Keeling SL. Duty to warn of genetic harm in breach of patient confidentiality. $J$ Law Med 2004: 12:235-53.

22 Patterson AR, Robinson LD, Naftalis EZ, Haley BB, Tomlinson GE. Custodianship of genetic information: clinical challenges and professional responsibility. J Clin Oncol 2005;23:2100-3.

23 Newson AJ, Humphries SE. Cascade testing in familial hypercholesterolaemia: how should family members be contacted? Eur J Hum Genet 2005;13:401-8.

24 Doukas DJ. Genetic providers and the family covenant: connecting individuals with their families. Genet Test 2003;7:315-21.

\section{PLEASE RETURN THIS FORM IN THE REPLY PAID ENVELOPE}

Your name:

Your date of birth:

Address:

Home phone:

Your signature:

Today's date:

Please indicate your decision (tick one box), sign the form, and send it back to us in the reply-paid envelope.

$\square$ I want an appointment with a genetic counsellor.

We recommend that you get a referral letter from your doctor for this appointment.

We will write to you doctor after your appointment.

$\square$ I do not want an appointment. Please contact my doctor. My doctor's name is

My doctor's address or suburb is

My doctor's telephone number is

If you do not want further information or an appointment at this stage, you are free to change your mind in the future.

The information provided will be kept in our files and it may be recorded in the database of the SA Clinical Genetics Service. Please keep us informed of any changes to this

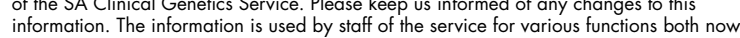
and in the future including clinical care of individuals and their families, administration, auditing clinical \& laboratory activities, and research. The database operates in accordance with the SA Department of Health's Code of Fair Information Practice.

Figure B Response sheet included with letter provided by the Familial Cancer Service. 